\title{
General Anaesthesia Protocols for Patients Undergoing Electroconvulsive Therapy Retrospective analysis of 504 sessions over a five-year period at a tertiary care hospital in Oman
}

"Aravind Narayanan, ${ }^{1}$ Chandar Lal, ${ }^{1}$ Hamed Al-Sinawi ${ }^{2}$

$$
\begin{aligned}
& \text { بروتوكلات التخدير العام للمرضى الذين يخضعون للعلاج بالجلسات الكهربائية }
\end{aligned}
$$

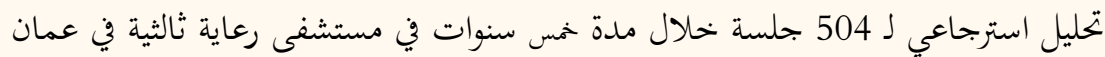

$$
\text { ارفيند ناريان، شندر لال، حمد السناوي }
$$

ABSTRACT: Objectives: This study aimed to review general anaesthesia protocols for patients undergoing electroconvulsive therapy (ECT) at a tertiary care hospital in Oman, particularly with regards to clinical profile, potential drug interactions and patient outcomes. Methods: This retrospective study took place at the Sultan Qaboos University Hospital (SQUH), Muscat, Oman. The electronic medical records of patients undergoing ECT at SQUH between January 2010 and December 2014 were reviewed for demographic characteristics and therapy details. Results: A total of 504 modified ECT sessions were performed on 57 patients during the study period. All of the patients underwent a uniform general anaesthetic regimen consisting of propofol and succinylcholine; however, they received different doses between sessions, as determined by the treating anaesthesiologist. Variations in drug doses between sessions in the same patient could not be attributed to any particular factor. Self-limiting tachycardia and hypertension were periprocedural complications noted among all patients. One patient developed aspiration pneumonitis (1.8\%). Conclusion: All patients undergoing ECT received a general anaesthetic regimen including propofol and succinylcholine. However, the interplay of anaesthetic drugs with ECT efficacy could not be established due to a lack of comprehensive data, particularly with respect to seizure duration. In addition, the impact of concurrent antipsychotic therapy on anaesthetic dose and subsequent complications could not be determined.

Keywords: General Anesthesia; Propofol; Succinylcholine; Electroconvulsive Therapy; Drug Interactions; Oman.

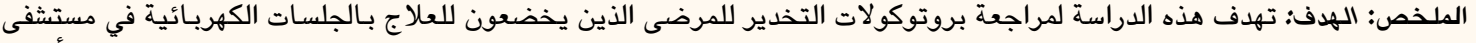

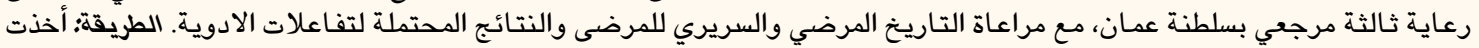

$$
\begin{aligned}
& \text { الكلمات المفتاحية: التخدير العام؛ البربوفول؛ السكيسنيل؛ العلاج بـالجلسات الكهربائية؛ تفاعل الادوية؛ عمان. }
\end{aligned}
$$

\section{ADVANCES IN KNOWLEDGE}

To the best of the authors' knowledge, this study is the first to evaluate anaesthesia protocols among patients undergoing modified electroconvulsive therapy (ECT) in Oman.

\section{Application to Patient Care}

Correlating antipsychotic and anaesthetic drug protocols with the quality and duration of ECT-induced seizures may help caregivers choose more suitable pharmaceutical agents.

The findings of the current study may help in creating standard protocols for the safe administration of anaesthetic agents during ECT treatment. 
$\mathrm{I}$ CLINICAL PRACTICE, THE CONCEPT OF inducing convulsions was first introduced in 1934 when camphor oil was used to induce convulsions in a patient with catatonic schizophrenia; electricallyinduced seizures were subsequently reported in 1938. ${ }^{1-6}$ In 1951, the use of general anaesthesia with muscle relaxants during electroconvulsive therapy (ECT) was proposed to alleviate the adverse effects and injuries resulting from seizure-induced motor activity, such as tongue biting and long bone fractures. ${ }^{7}$ Currently, performing ECT on a patient without anaesthesia is considered unethical. ${ }^{8}$ During ECT sessions, anaesthesiologists provide diligent cardiorespiratory monitoring services, life support expertise and the pharmacological reduction of actual seizures while allowing unimpeded electrical activity. ${ }^{9}$

Globally, anaesthesia protocols during ECT procedures are not standardised, primarily due to the varying availability of drugs and the preferences of individual anaesthetic care providers. ${ }^{10}$ However, the increasing number of psychopharmaceutical drugs available necessitates greater vigilance with regards to possible interactions with anaesthetic agents so as to avoid the development of cardiovascular complications. ${ }^{11}$ Moreover, the expanding geriatric population worldwide and the increasing burden of chronic diseases like diabetes, hypertension and ischaemic heart disease are also added risk factors for the increased incidence of adverse effects and drug interactions due to anaesthesia and ECT. A thorough understanding of pre-existing medical conditions is needed when determining the selection of suitable anaesthetic drugs, monitoring options and management of complications arising from anaesthesia and induced seizures. ${ }^{12}$ Anaesthetic drugs alone should not cause added complications or attenuate the efficacy of the seizure therapy. ${ }^{13}$

It is imperative for anaesthesia care providers to refine management strategies and treatment regimens for patients undergoing ECT sessions, thus ensuring the safety and comfort of the patient and enhancing overall acceptance of ECT. This study aimed to analyse the anaesthesia protocols used during modified ECT sessions at a tertiary care hospital in Oman over a five year period and determine patient outcomes, periprocedural complications and potential correlations with demographic, clinical, pharmacological and therapeutic factors. By identifying potential deficits in existing anaesthesia protocols, more objective anaesthetic and psychopharmaceutical treatment plans can be determined, which could then be extended into a region-based standard of care.

\section{Methods}

This retrospective study was conducted at the Sultan Qaboos University Hospital (SQUH), Muscat, Oman. The electronic medical records of all patients receiving ECT at SQUH between January 2010 and December 2014 were analysed. Information was collected regarding demographic characteristics, psychiatric diagnosis, the presence of any comorbidities at the time of ECT treatment, physical status as per American Society of Anaesthesiologists (ASA) classifications, overall number of ECT sessions performed and type of anaesthetic drugs used during the ECT session. ${ }^{14}$ Patients with critical illnesses or with ASA grades of $\geq$ III were deemed unfit for ECT and excluded from the study.

All of the patients were assessed the day before the ECT session by a trained anaesthesiologist. Any use of antipsychotic drugs for primary behavioural disorders was documented, especially with regards to concomitant use immediately preceding the ECT session. Additional sedative premedication was not prescribed by the anaesthesiologist for any patient. The ECT procedures were conducted in the operation theatre recovery room by a behavioural medicine specialist, an anaesthesiologist and an anaesthesia nurse. A complete set of resuscitation equipment and drugs along with a piped oxygen supply and central suction unit were available on-hand. Before induction of the anaesthesia, intravenous (IV) access was ensured and monitoring equipment was connected. Bitemporal electrical shocks were delivered using a Thymatron ${ }^{\circledR}$ System IV Integrated ECT Instrument (Somatics LLC, Lake Bluff, Illinois, USA). After the ECT procedure, the patients were monitored until they were transferred to a general ward.

Data were tabulated using an Excel spreadsheet, Version 2013 (Microsoft Inc., Redmond, Washington, USA) and analysed statistically using the Statistical Package for the Social Sciences (SPSS), Version 23 (IBM Corp., Chicago, Illinois, USA). As some inpatients were admitted more than once, each admission period was considered an episode. For those patients receiving several sessions of maintenance ECT as outpatients, these were recorded as sessions but not episodes. Drug dosing was interpreted according to $\mathrm{kg}$ of body weight for comparative purposes.

Ethical approval for this study was granted by the Medical Ethics Committee of the College of Medicine \& Health Sciences at Sultan Qaboos University (MREC \#911). Patient confidentiality was maintained by coding the medical records to conceal patient identity. 
Table 1: Demographic and clinical variables of patients undergoing electroconvulsive therapy sessions at the Sultan Qaboos University Hospital, Muscat, Oman, according to gender $(\mathrm{N}=57)$

\begin{tabular}{|c|c|c|c|c|c|}
\hline \multirow[t]{2}{*}{ Variable } & \multicolumn{2}{|c|}{ Mean \pm SD } & \multicolumn{3}{|c|}{ Inter-gender comparison } \\
\hline & Females $(n=37)$ & Males $(n=20)$ & T value* & $\begin{array}{c}\text { Mann- } \\
\text { Whitney U }\end{array}$ & $P$ value \\
\hline Age in years & $42.7 \pm 18.9$ & $45.1 \pm 17.7$ & -0.470 & - & 0.640 \\
\hline Height in $\mathrm{m}$ & $1.54 \pm 0.06$ & $1.61 \pm 0.09$ & -3.299 & - & $0.002^{\dagger}$ \\
\hline Weight in kg & $64.9 \pm 16.6$ & $70.3 \pm 19.4$ & 1.102 & - & 0.275 \\
\hline $\mathrm{BMI}$ in $\mathrm{kg} / \mathrm{m}^{2}$ & $27.2 \pm 6.4$ & $26.9 \pm 6.6$ & 0.131 & - & 0.896 \\
\hline ECT sessions (range) & $8.9 \pm 19(4-23)$ & $8.6 \pm 21(2-23)$ & 0.208 & - & 0.836 \\
\hline Hospital stay in days (range) & $34.5 \pm 99(8-107)$ & $37.1 \pm 58(7-65)$ & 0.427 & - & 0.671 \\
\hline Post-ECT hospital stay in days (range) & $4.0(0-36)$ & $4.3(0-17)$ & 0.196 & - & 0.845 \\
\hline \multicolumn{6}{|l|}{ ASA status, n (\%) } \\
\hline Grade 1 & $28(49.1)$ & $17(29.8)$ & - & 331 & 0.341 \\
\hline Grade 2 & $5(8.8)$ & $3(5.3)$ & & & \\
\hline Grade 3 & $4(7.0)$ & $0(0.0)$ & & & \\
\hline \multicolumn{6}{|l|}{ Propofol dose in $\mathrm{mg} / \mathrm{kg}$} \\
\hline Minimum & $1.36 \pm 0.38$ & $1.38 \pm 0.29$ & - & 404 & 0.567 \\
\hline Maximum & $1.94 \pm 0.45$ & $1.94 \pm 0.52$ & - & 366.5 & 0.953 \\
\hline \multicolumn{6}{|l|}{ Succinylcholine dose in $\mathrm{mg} / \mathrm{kg}$} \\
\hline Minimum & $0.64 \pm 0.17$ & $0.64 \pm 0.15$ & - & 369 & 0.986 \\
\hline Maximum & $0.84 \pm 0.23$ & $0.87 \pm 0.26$ & - & 379 & 0.879 \\
\hline
\end{tabular}

$B M I=$ body mass index; $E C T=$ electroconvulsive therapy; $A S A=$ American Society of Anaesthesiologists.

*Using t(55). ${ }^{\dagger}$ Statistically significant.

\section{Results}

During the study period, a total of 504 ECT sessions were performed on 57 patients, including 20 male and 37 female patients. Among these patients, a total of 71 episodes (admission periods) were noted, with 10 inpatients having two episodes and four inpatients having three episodes or more. Male and female patients were statistically comparable in terms of age, weight and body mass index; however, men were significantly taller than women $(P=0.002)$. The mean number of ECT sessions per patient was 8.8 (range: 2-23 sessions). The mean hospital stay duration was 35.8 days prior to the completion of ECT treatment and 4.2 days after the final ECT session [Table 1].

Among the patients who underwent ECT during the study period, 34 patients (59.6\%) were diagnosed with major depression, 10 (17.5\%) with schizophrenia and seven (12.3\%) with bipolar disorder. The remaining six patients (10.5\%) had postpartum behavioural and/ or obsessive-compulsive disorders. The majority of the patients had no comorbid illnesses and were classified as ASA grade I ( $\mathrm{n}=45 ; 78.9 \%)$. There were 12 patients $(21.1 \%)$ classified as ASA grade II or III
Table 2: Prevalence of comorbid diseases among patients undergoing electroconvulsive therapy at the Sultan Qaboos University Hospital, Muscat, Oman $(\mathrm{N}=57)$

$\begin{array}{lc}\text { Comorbid illness } & \mathbf{n}(\mathbf{\%})^{*} \\ \text { Hypertension } & 5(8.8) \\ \text { Diabetes } & 4(7.0) \\ \text { Ischaemic heart disease } & 3(5.3) \\ \text { Liver cirrhosis } & 1(1.8) \\ \text { Obesity-related sleep apnoea } & 1(1.8) \\ \text { Gastric ulcer } & 1(1.8) \\ \text { Chronic nephritis } & 1(1.8) \\ \text { Breast carcinoma } & 1(1.8) \\ \text { Hypothyroidism } & 1(1.8)\end{array}$

*Patients with more than one comorbid illness have been included in several categories.

in terms of physical status. Six patients had a single systemic disease, while the remaining six had two or more illnesses, with the most common being diabetes, hypertension and controlled ischaemic heart disease [Table 2]. 
Table 3: Complications*, management and patient outcomes of electroconvulsive therapy sessions at the Sultan Qaboos University Hospital, Muscat, Oman $(\mathrm{N}=504)$

\begin{tabular}{|c|c|c|c|}
\hline Complication & n (\%) & $\begin{array}{l}\text { Management } \\
\text { (dose) }\end{array}$ & $\begin{array}{c}\text { Patient } \\
\text { outcome }\end{array}$ \\
\hline Facial flush & $1(0.2)$ & $\begin{array}{l}\text { Continuous } \\
\text { monitoring }\end{array}$ & Self-limiting \\
\hline Tachycardia & $2(0.4)$ & Esmolol (50 mg) & $\begin{array}{l}\text { Control of } \\
\text { symptom }\end{array}$ \\
\hline Bradycardia & $2(0.4)$ & Atropine $(0.5 \mathrm{mg})$ & $\begin{array}{l}\text { Control of } \\
\text { symptom }\end{array}$ \\
\hline Hypersalivation & $4(0.8)$ & $\begin{array}{c}\text { Glycopyrrolate } \\
(0.4 \mathrm{mg})\end{array}$ & $\begin{array}{l}\text { Control of } \\
\text { symptom }\end{array}$ \\
\hline Hypertension & $2(0.4)$ & Labetalol (10 mg) & $\begin{array}{l}\text { Control of } \\
\text { symptom }\end{array}$ \\
\hline Hypotension & $1(0.2)$ & Ephedrine (5 mg) & $\begin{array}{l}\text { Control of } \\
\text { symptom }\end{array}$ \\
\hline $\begin{array}{l}\text { Delayed } \\
\text { recovery }\end{array}$ & $1(0.2)$ & $\begin{array}{l}\text { Continuous } \\
\text { monitoring }\end{array}$ & $\begin{array}{l}\text { Complete } \\
\text { recovery }\end{array}$ \\
\hline Hyperglycaemia & $1(0.2)$ & $\begin{array}{l}\text { IV insulin } \\
\text { (10 units) with } \\
\text { blood glucose } \\
\text { monitoring }\end{array}$ & $\begin{array}{l}\text { Control } \\
\text { of blood } \\
\text { glucose to } \\
<10 \mathrm{mmol}\end{array}$ \\
\hline $\begin{array}{l}\text { Sustained } \\
\text { seizures }\end{array}$ & $1(0.2)$ & Propofol (20 mg) & $\begin{array}{l}\text { Control of } \\
\text { seizures }\end{array}$ \\
\hline $\begin{array}{l}\text { Aspiration } \\
\text { pneumonitis }\end{array}$ & $1(0.2)$ & $\begin{array}{l}\text { Non-invasive } \\
\text { ventilation and } \\
\text { antibiotics }\end{array}$ & $\begin{array}{l}\text { Patient } \\
\text { recovered } \\
\text { and was } \\
\text { discharged } \\
\text { from hospital }\end{array}$ \\
\hline Machine failure & $1(0.2)$ & $\begin{array}{c}\text { ECT was not } \\
\text { delivered }\end{array}$ & $\begin{array}{l}\text { Patient } \\
\text { recovered } \\
\text { from } \\
\text { anaesthesia }\end{array}$ \\
\hline
\end{tabular}

$I V=$ intravenous; $E C T=$ electroconvulsive therapy.

"Including only those complications which required additional medication or management.

Every patient received between one and five sedative drugs before each ECT session as part of their psychiatric medical therapy. As numerous adjustments were made to the doses due to changes in the clinical condition of each patient, definitive premedication doses were not recorded. Atropine was not used as routine premedication for any of the patients. During the ECT sessions, all of the patients were attended by a trained staff anaesthesiologist and intravenously received propofol as an anaesthetic agent and succinylcholine as a muscle relaxant. Propofol doses ranged from $1.36-1.94 \mathrm{mg} / \mathrm{kg}$ with individual doses titrated to clinical loss of consciousness by the attending anaesthesiologist. Variations in dosing were noted between different ECT sessions for the same patient in subsequent episodes; however, these variations could not be attributed to any particular factor. Mean doses of succinylcholine ranged between $0.64-0.87 \mathrm{mg} / \mathrm{kg}$. Subsequent doses of succinylcholine during later ECT sessions for the same patient were tailored according to the clinical observations of the attending anaesthesiologist and the behavioural medicine team. Electrocardiography (ECG) monitoring took place throughout all ECT sessions. In addition, pulse, heart rate, blood oxygen saturation and automated non-invasive blood pressure were monitored at regular intervals during the session.

During the ECT procedure, transient tachycardia and hypertension were observed in all patients, initially after the succinylcholine administration and then during the clonic phase of the seizures, following the initial parasympathetic activity of the tonic phase. Intravenous lidocaine was administered prophylactically to one patient (1.8\%) with a history of frequent premature ventricular contractions, which did not lead to haemodynamic instability. Table 3 presents a summary of the peri- and postprocedural complications which required additional medication or management. Beta-blocker therapy was required for five patients (8.8\%), although not during all ECT sessions for each patient. Transient bradycardia and hypersalivation were documented in two $(3.5 \%)$ and four patients (7.0\%), respectively; the development of these complications were not related to ASA grade severity. After the ECT procedure, glycopyrrolate was administered to four patients (7.0\%) to reduce profuse oral secretions and atropine was administered to one patient (1.8\%) due to persistent bradycardia. Another patient with a pre-existing atrial fibrillation was diagnosed with bradycardia after the ECT procedure but did not require atropine therapy.

Sustained seizure activity was documented in one patient (1.8\%) classified as ASA grade I who needed an additional propofol dose and a higher succinylcholine dose in subsequent ECT sessions. One ECT session $(0.2 \%)$ was aborted after the administration of anaesthetic drugs as the ECT energy delivery unit malfunctioned. Delayed recovery was documented in one patient (1.8\%) classified as ASA grade I. One patient $(1.8 \%)$ went into respiratory distress and oxygen desaturation after his third ECT session which presented within an hour of being moved from the recovery room. The initial diagnosis of a pulmonary embolism was ruled out by chest imaging and a subsequent diagnosis of aspiration pneumonitis was made, likely due to diabetes-related gastroparesis. The patient was given supplemental oxygen and noninvasive ventilatory support in a high-dependency ward and was prescribed a five-day course of antibiotics. He was subsequently discharged from the hospital after a complete recovery.

Anaesthetic regimens could not be correlated with patient outcomes. Unfortunately, information 
regarding the energy level of shocks delivered and seizure duration was unavailable for any of the patients, presumably due to equipment constraints. As such, the effect of the anaesthetic drugs on the efficacy of ECT could not be established. The effect of concurrent antipsychotic therapy on anaesthetic drug dose and subsequent complications could also not be determined.

\section{Discussion}

In spite of its mechanism of action, ECT is one of the safest therapeutic procedures for the treatment of mental illness, with reported post-treatment mortality rates of 1:25,000-50,000. ${ }^{3}$ Nevertheless, care providers should remain vigilant as induced seizures affect the cardiorespiratory and autonomic systems; although transient, these physiological effects pose a serious hazard, particularly to elderly patients or those with multiple comorbidities..$^{15}$ According to previous research, ECT is currently available in 23 Asian countries; however, the use of this type of therapy in the Asian region is considered critically suboptimal in terms of conduct, monitoring and training. ${ }^{16}$ In the Middle East, objective studies of mental illness-and, more specifically, the use of ECT and associated anaesthetic regimens-have not yet been conducted. ${ }^{17}$ A 10-year audit of ECT treatment at a university hospital in Saudi Arabia is currently the largest body of work on this topic in the Arab region. ${ }^{18}$ As such, to the best of the authors' knowledge, this is the first study to evaluate the use of anaesthesia among patients undergoing ECT in Oman.

The use of anaesthetic agents during ECT, primarily central nervous system (CNS) depressors which attenuate the intensity/duration of seizures, has been widely researched. ${ }^{19}$ In general, most anaesthetic agents depress the CNS, thus ironically countering the objective of ECT, which is to excite the CNS and induce seizures..$^{20}$ Although methohexital and sodium thiopental were previously the most frequently used anaesthetic agents for ECT, these drugs have now been largely replaced by propofol due to its wider availability, faster recovery profile and favourable effect on haemodynamic stability, despite its effect in reducing seizure production. ${ }^{19,21}$ Other inhalational anaesthetic agents have been compared favourably with propofol. ${ }^{22}$ Ketamine and etomidate do not have anticonvulsant properties and seem to provide a higher quality and duration of seizures. ${ }^{23,24}$ However, associated side-effects such as hallucinations, sympathetic activation of the nervous system and hypothalamic depression have excluded their routine use during ECT treatment. ${ }^{25}$ Numerous adjuncts to induction agents have been suggested so as to reduce the required dose of propofol and provide good sedation depth and seizure quality; remifentanil, a novel ultra-short-acting opioid, has a favourable profile in this respect. ${ }^{26}$

The current study sought to correlate concomitant use of antipsychotic medications with anaesthesia dosages during ECT sessions in order to determine a pattern which might allow the clinical utilisation of a narrower dosage range. This would eliminate dose variations between anaesthesiologists and be more objective and safe for general patient use. Concomitant antipsychotic drugs (e.g. benzodiazepines) have been implicated in raising the seizure threshold, thus reducing the overall efficacy of ECT; in such patients, cognitive function should be monitored on an on-going basis or at least after each ECT course, as recommended in the National Institute of Clinical Excellence guidelines. ${ }^{27}$ Unfortunately, the varied drug regimens and dosages and differing clinical conditions of the patients in the current study made it difficult to determine a statistical or clinical correlation with either anaesthetic drug dose or ECT efficacy. In addition, the short-acting muscle relaxant succinylcholine minimises physical musculoskeletal manifestations of induced seizures, while allowing seizure activity to proceed in the brain tissue. ${ }^{28}$ This complete attenuation of the clinical signs of a seizure means that the only way to record seizure duration is by electroencephalography (EEG). In the current study, seizure duration could not established either via clinical observation or EEG recordings, due to a lack of proper equipment and the absence of a specific clinical directive. This precluded any correlation between anaesthetic drug doses and attenuation of seizure intensity or duration. Finally, the dose of electrical energy delivered during ECT sessions in the current study was not recorded in the patients' medical records. Analysis of the energy dose, in correlation with the seizure duration and the anaesthetic drug dose, would have provided a good measure of the efficacy and robustness of the anaesthetic regimen used for ECT. ${ }^{9}$

Succinylcholine is the gold standard for modified ECT sessions. ${ }^{28}$ As mentioned earlier, it is recommended that the lowest possible dose of muscle relaxants be used so as to maintain minimal muscle fasciculation and obtain visual evidence of seizures. ${ }^{29}$ The goal is to prevent massive tonic-clonic seizures resulting in movements that could lead to soft tissue/ bony injury, rhabdomyolysis or hyperkalemia. In situations where a depolarising muscle relaxant is contraindicated, such as with paraplegia, stroke, hyperkalemic syndromes and major trauma/burns, 
rocuronium has been administered with rapid reversal of its neuromuscular blockade using the novel cyclodextrin agent sugammadex. ${ }^{30}$ Low-dose atropine has been advocated to counter transient parasympathetic-mediated dysrhythmia and increased exocrine secretions after ECT. ${ }^{31}$ However, given the arid environment and high ambient temperatures of the Middle East, the potential thermogenic action of parasympatholytic agents precludes their routine use as a premedication..$^{32}$ Additionally, patients undergoing ECT are usually also prescribed various antipsychotic agents known to trigger the serotonin-mediated hypothalamic resetting of body temperature-control mechanisms. ${ }^{33}$ Beta-blockers such as esmolol or labetalol are the mainstay of therapy for the management of hypertension and tachyarrhythmia, which are usually persistent after ECT is administered. ${ }^{34}$ However, esmolol has a doserelated effect of shortening the duration of a seizure, with minimal impact on EEG measurements. In comparison, the novel alpha agonist dexmedetomidine has been shown to more favourably reduce the hyperdynamic circulatory response after ECT. ${ }^{35}$

During short anaesthesia sessions for ECT, patients undergo ventilation with a face mask or positive pressure ventilation with a bag-mask device, without definitive airway protection devices; this is because the procedure is always performed on an elective basis and with an adequate fasting period, obviating the need for such interventions. However, due to seizure-induced relaxation of the oesophageal sphincter, patients with oesophageal reflux disease or gastric dysmotility/gastroparesis due to diabetic or autonomic neuropathy are likely candidates for aspiration while unconscious. Hence, it is necessary to monitor oxygen saturation throughout the procedure so as to detect possible life-threatening episodes of desaturation. ${ }^{36}$ Sudden cardiac death has also been reported following ECT, likely due to proarrhythmogenic interactions between antipsychotic medications and the application of electrical energy; hence, there is a need for diligent pre-anaesthetic and periprocedural 12-lead ECG monitoring. ${ }^{37}$ Using bispectral index monitoring to determine sedation depth and titrate anaesthetic agents is a promising new technology in ensuring patient safety during ECT sessions. ${ }^{38}$ Novel shorter-acting adjunctive pharmacologic agents also need to be explored, particularly for patients undergoing ECT who present at an older age or with comorbidities. ${ }^{18}$

A major limitation of the present study was the lack of documentation regarding the energy level, number and duration of the electric shocks delivered during ECT sessions, particularly with regards to the lack of EEG data. Moreover, the use of differing primary antipsychotic drug regimens in patients, many with additional anti-seizure activities, confounded attempts to identify optimum anaesthetic drug doses for seizure quality and duration and precluded more objective correlations with the anaesthetic drug doses used. In order to determine safer and more objective anaesthesia protocols, prospective studies are recommended to correlate energy levels of electric shocks delivered during ECT, seizure duration, concomitant antipsychotic agents and overall patient outcomes.

\section{Conclusion}

All ECT sessions in the current study were conducted using a uniform anaesthesia protocol consisting of propofol and succinylcholine. Wide dosage variations were observed among patients and between different sessions for the same patient. No specific factor could explain these variations, nor could the anaesthetic regimen be correlated with eventual patient outcomes. Increased oral secretions and transient tachycardia, bradycardia and hypertension were the most common periprocedural complications, which did not necessitate any major change in the anaesthetic regimen. Due to a lack of data with regards to the energy level, number and duration of the electric shocks delivered during ECT sessions, correlations between anaesthetic drugs and ECT efficacy could not be established. Furthermore, the impact of concurrent antipsychotic therapy on anaesthetic regimen and patient outcomes could not be determined.

\section{CONFLICT OF INTEREST}

The authors declare no conflicts of interest.

\section{FUNDING}

No funding was received for this study.

\section{References}

1. Faedda GL, Becker I, Baroni A, Tondo L, Asplund E, Koukopoulos A. The origins of electroconvulsive therapy: Prof. Bini's first report on ECT. J Affect Disord 2010; 120:12-15. doi: 10.1016/j.jad.2009.01.023.

2. Mayo C, Kaye AD, Conrad E, Baluch A, Frost E. Update on anaesthesia considerations for electroconvulsive therapy. Middle East J Anaesthesiol 2010; 20:493-8.

3. Baghai TC, Möller HJ. Electroconvulsive therapy and its different indications. Dialogues Clin Neurosci 2008; 10:105-17.

4. Spodniaková B, Halmo M, Nosálová P. Electroconvulsive therapy in pregnancy: A review. J Obstet Gynaecol 2015; 35:659-62. doi: 10.3109/01443615.2014.990427. 
5. Bolwig TG. How does electroconvulsive therapy work? Theories on its mechanism. Can J Psychiatry 2011; 56:13-18. doi: $10.1177 / 070674371105600104$

6. Lesage A, Lemasson M, Medina K, Tsopmo J, Sebti N, Potvin S, et al. The prevalence of electroconvulsive therapy use since 1973: A meta-analysis. J ECT 2016; 32:236-42. doi: 10.1097/YCT.0000000000000320

7. Wagner KJ, Möllenberg O, Rentrop M, Werner C, Kochs EF. Guide to anaesthetic selection for electroconvulsive therapy. CNS Drugs 2005; 19:745-58. doi: 10.2165/00023210-2005 19090-00002.

8. Andrade C, Shah N, Tharyan P, Reddy MS, Thirunavukarasu M, Kallivayalil RA, et al. Position statement and guidelines on unmodified electroconvulsive therapy. Indian J Psychiatry 2012; 54:119-33. doi: 10.4103/0019-5545.99530.

9. Peterchev AV, Rosa MA, Deng ZD, Prudic J, Lisanby SH. Electroconvulsive therapy stimulus parameters: Rethinking dosage. J ECT 2010; 26:159-74. doi: 10.1097/YCT.0b013e $3181 \mathrm{e} 48165$.

10. Leiknes KA, Jarosh-von Schweder L, Høie B. Contemporary use and practice of electroconvulsive therapy worldwide. Brain Behav 2012; 2:283-344. doi: 10.1002/brb3.37.

11. Attri JP, Bala N, Chatrath V. Psychiatric patient and anaesthesia Indian J Anaesth 2012; 56:8-13. doi: 10.4103/0019-5049.93337.

12. Sundsted KK, Burton MC, Shah R, Lapid MI. Preanesthesia medical evaluation for electroconvulsive therapy: A review of the literature. J ECT 2014; 30:35-42. doi: 10.1097/YCT.0b0 13e3182a3546f.

13. Saito S. Anesthesia management for electroconvulsive therapy: Hemodynamic and respiratory management. J Anesth 2005; 19:142-9. doi: 10.1007/s00540-004-0288-7.

14. Daabiss M. American Society of Anaesthesiologists physical status classification. Indian J Anaesth 2011; 55:111-15. doi: 10. 4103/0019-5049.79879.

15. Cristancho MA, Alici Y, Augoustides JG, O’Reardon JP. Uncommon but serious complications associated with electroconvulsive therapy: Recognition and management for the clinician. Curr Psychiatry Rep 2008; 10:474-80. doi: 10.1007/s11920-008-0076-4.

16. Chanpattana W, Kramer BA, Kunigiri G, Gangadhar BN, Kitphati R, Andrade C. A survey of the practice of electroconvulsive therapy in Asia. J ECT 2010; 26:5-10. doi: 10.1097/YCT.0b013e3181a74368.

17. Al-Adawi S, Dorvlo AS, Al-Ismaily SS, Al-Ghafry DA, AlNoobi BZ, Al-Salmi A, et al. Perception of and attitude towards mental illness in Oman. Int J Soc Psychiatry 2002; 48:305-17. doi: $10.1177 / 002076402128783334$.

18. Alhamad AM, al-Haidar F. A retrospective audit of electroconvulsive therapy at King Khalid University Hospital, Saudi Arabia. East Mediterr Health J 1999; 5:255-61.

19. Lihua P, Su M, Ke W, Ziemann-Gimmel P. Different regimens of intravenous sedatives or hypnotics for electroconvulsive therapy (ECT) in adult patients with depression. Cochrane Database Syst Rev 2014; CD009763. doi: 10.1002/14651858. CD009763.pub2.

20. Canbek O, Ipekcioglu D, Menges OO, Atagun MI Karamustafalıglu N, Cetinkaya OZ, et al. Comparison of propofol, etomidate, and thiopental in anesthesia for electroconvulsive therapy: A randomized, double-blind clinical trial. J ECT 2015; 31:91-7. doi: 10.1097/YCT.00000 00000000190 .

21. Jarineshin H, Kashani S, Fekrat F, Vatankhah M, Golmirzaei J, Alimolaee E, et al. Seizure duration and hemodynamic state during electroconvulsive therapy: Sodium thiopental versus propofol. Glob J Health Sci 2015; 8:126-31. doi: 10.5539/gjhs. v8n2p126.
22. Wang X, Chen Y, Zhou X, Liu F, Zhang T, Zhang C. Effects of propofol and ketamine as combined anesthesia for electroconvulsive therapy in patients with depressive disorder. J ECT 2012; 28:128-32. doi: 10.1097/YCT.0b013e31824d1d02.

23. Rybakowski JK, Bodnar A, Krzywotulski M, ChlopockaWozniak M, Michalak M, Rosada-Kurasinska J, et al. Ketamine anesthesia, efficacy of electroconvulsive therapy, and cognitive functions in treatment-resistant depression. J ECT 2016; 32:164-8. doi: 10.1097/YCT.0000000000000317.

24. Ayhan Y, Akbulut BB, Karahan S, Gecmez G, Öz G, Gurel SC, et al. Etomidate is associated with longer seizure duration, lower stimulus intensity, and lower number of failed trials in electroconvulsive therapy compared with thiopental. J ECT 2015; 31:26-30. doi: 10.1097/YCT.0000000000000149.

25. Hoyer C, Kranaster L, Janke C, Sartorius A. Impact of the anesthetic agents ketamine, etomidate, thiopental, and propofol on seizure parameters and seizure quality in electroconvulsive therapy: A retrospective study. Eur Arch Psychiatry Clin Neurosci 2014; 264:255-61. doi: 10.1007/s00406-013-0420-5.

26. MacPherson R, Marroquin-Harris M, Gálvez V, Tor P, Loo C. The effect of adjuvant remifentanil with propofol or thiopentone on seizure quality during electroconvulsive therapy. Anaesth Intensive Care 2016; 44:278-80.

27. Shah A. The impact of the National Institute of Clinical Excellence guidance on the use of electroconvulsive therapy in England. Int Psychogeriatr 2010; 22:164-6. doi: 10.1017/ S1041610209990809.

28. Zolezzi M. Medication management during electroconvulsant therapy. Neuropsychiatr Dis Treat 2016; 12:931-9. doi: 10.2147/ NDT.S100908

29. Mirzakhani H, Guchelaar HJ, Welch CA, Cusin C, Doran ME, MacDonald TO, et al. Minimum effective doses of succinylcholine and rocuronium during electroconvulsive therapy: A prospective, randomized, crossover trial. Anesth Analg 2016; 123:587-96. doi: 10.1213/ANE.0000000000001218.

30. Chow TK. Titration of electroconvulsive therapy: The use of rocuronium and sugammadex with adjunctive laryngeal mask. Br J Anaesth 2012; 108:882-3. doi: 10.1093/bja/aes115.

31. Anastasian ZH, Khan N, Heyer EJ, Berman MF, Ornstein E, Prudic J, et al. Effect of atropine dose on heart rate during electroconvulsive therapy. J ECT 2014; 30:298-302. doi: 10.10 97/YCT.0000000000000123.

32. Sessler DI. Temperature monitoring and perioperative thermoregulation. Anesthesiology 2008; 109:318-38. doi: 10.10 97/ALN.0b013e31817f6d76.

33. Cheng YC, Liang CM, Liu HC. Serotonin syndrome after electroconvulsive therapy in a patient on trazodone, bupropion, and quetiapine: A case report. Clin Neuropharmacol 2015; 38:112-13. doi: 10.1097/WNF.0000000000000076.

34. Boere E, Birkenhäger TK, Groenland TH, van den Broek WW. Beta-blocking agents during electroconvulsive therapy: A review. Br J Anaesth 2014; 113:43-51. doi: 10.1093/bja/aeu153.

35. Aydogan MS, Yücel A, Begec Z, Colak YZ, Durmus M. The hemodynamic effects of dexmedetomidine and esmolol in electroconvulsive therapy: A retrospective comparison. J ECT 2013; 29:308-11. doi: 10.1097/YCT.0b013e3182972bec.

36. Surve R, Bansal S, Sriganesh K, Subbakrishna DK, Thirthalli J, Umamaheswara Rao GS. Incidence and risk factors for oxygen desaturation during recovery from modified electroconvulsive therapy: A prospective observational study. J Anaesthesiol Clin Pharmacol 2015; 31:99-103. doi: 10.4103/0970-9185.150555.

37. Wang Z, Wang J. Sudden cardiac death after modified electroconvulsive therapy. Shanghai Arch Psychiatry 2015; 27:315-18. doi: 10.11919/j.issn.1002-0829.214169.

38. Kranaster L, Hoyer C, Janke C, Sartorius A. Bispectral index monitoring and seizure quality optimization in electroconvulsive therapy. Pharmacopsychiatry 2013; 46:147-50. doi: $10.1055 / \mathrm{s}-0032-1331748$. 